\title{
BMJ Open What are the barriers to implementation of cardiopulmonary resuscitation training in secondary schools? A qualitative study
}

\author{
Line Zinckernagel, ${ }^{1}$ Carolina Malta Hansen, ${ }^{2}$ Morten Hulvej Rod, ${ }^{1}$ Fredrik Folke, ${ }^{2,3}$
} Christian Torp-Pedersen, ${ }^{4}$ Tine Tjørnhøj-Thomsen ${ }^{1}$

To cite: Zinckernagel L, Malta Hansen C, Rod MH, et al. What are the barriers to implementation of cardiopulmonary resuscitation training in secondary schools? A qualitative study. BMJ Open 2016:6:e010481. doi:10.1136/bmjopen-2015010481

- Prepublication history and additional material is available. To view please visit the journal (http://dx.doi.org/ 10.1136/bmjopen-2015010481)

Received 6 November 2015 Revised 11 January 2016 Accepted 2 February 2016

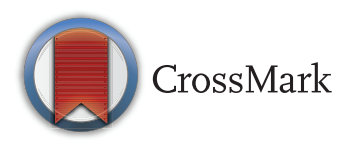

For numbered affiliations see end of article.

Correspondence to Line Zinckernagel; lizi@niph.dk

\section{ABSTRACT}

Objective: Cardiopulmonary resuscitation (CPR) training in schools is recommended to increase bystander CPR and thereby survival of out-of-hospital cardiac arrest, but despite mandating legislation, low rates of implementation have been observed in several countries, including Denmark. The purpose of the study was to explore barriers to implementation of CPR training in Danish secondary schools.

Design: A qualitative study based on individual interviews and focus groups with school leadership and teachers. Thematic analysis was used to identify regular patterns of meaning both within and across the interviews.

Setting: 8 secondary schools in Denmark. Schools were selected using strategic sampling to reach maximum variation, including schools with/without recent experience in CPR training of students, public/ private schools and schools near to and far from hospitals.

Participants: The study population comprised 25 participants, 9 school leadership members and 16 teachers.

Results: School leadership and teachers considered it important for implementation and sustainability of CPR training that teachers conduct CPR training of students. However, they preferred external instructors to train students, unless teachers acquired the CPR skills which they considered were needed. They considered CPR training to differ substantially from other teaching subjects because it is a matter of life and death, and they therefore believed extraordinary skills were required for conducting the training. This was mainly rooted in their insecurity about their own CPR skills. CPR training kits seemed to lower expectations of skill requirements to conduct CPR training, but only among those who were familiar with such kits.

Conclusions: To facilitate implementation of CPR training in schools, it is necessary to have clear guidelines regarding the required proficiency level to train students in CPR, to provide teachers with these skills, and to underscore that extensive skills are not required to provide CPR. Further, it is important to familiarise teachers with CPR training kits.

\section{Strengths and limitations of this study}

- The qualitative design of our study allowed us to gain an in-depth and nuanced understanding of why implementation of cardiopulmonary resuscitation (CPR) training in schools has been unsuccessful despite mandating legislation.

- We were able to reveal new important barriers, get insight into the complex relationship between barriers, and to reach an understanding of the underlying mechanisms related to previously identified barriers.

- We managed to obtain a broad representation of schools and interviewees, to portray different positions, and reached data saturation.

- The study did not explore how schools currently providing CPR training of students had implemented and conducted the training, though this could inspire and give directions for other schools.

\section{INTRODUCTION}

Out-of-hospital cardiac arrest (OHCA) is a major public health problem affecting 700000 persons in Europe and North America annually, ${ }^{1}{ }^{2}$ and the overall survival rate is generally less than $10 \% \cdot{ }^{1-3}$ Early initiation of cardiopulmonary resuscitation (CPR) can increase survival rates markedly, ${ }^{4}$ and this places bystanders in a central role. However, only about $30 \%$ of patients receive CPR before the arrival of the Emergency Medical Services. ${ }^{4-7}$

CPR training in schools has been identified as an essential component to raise bystander CPR rates, because it will ensure that a large proportion of the population is CPR trained. ${ }^{18-12}$ Several organisations, such as the European Parliament and the WHO, therefore recommend CPR training in secondary schools and encourage national legislation. ${ }^{1}{ }^{8-12}$ In 2013, 4 of 16 surveyed 
European countries had made CPR training an official learning outcome for primary/secondary schools, ${ }^{12}$ and in the USA, 20 states have currently mandated CPR training by graduation of high school. ${ }^{1}{ }^{8-12}$

Denmark was one of the first countries to approve mandating legislation on CPR training in schools, stating that students should receive training before graduating from secondary school. ${ }^{13}{ }^{14}$ As in many other countries, Danish legislation provides no guidance regarding who should train the students, required trainer proficiency level, training material, training time, which part of the school curriculum CPR training should be integrated in or the source of funding. The importance of a framework providing such guidance has been underscored. ${ }^{15}$ The schools do not receive any financial benefits for adhering to the mandate of providing CPR training and there are no formally approved repercussions for not adhering. Nevertheless, it is the responsibility of the school leadership to implement the state law. ${ }^{13}$

Despite mandating legislation, low rates of implementation of CPR training in schools have been observed in several countries, including Denmark. ${ }^{16}{ }^{17}$ Thus, other barriers seem important to address in parallel to promoting legislation to ensure CPR training of students. Little is known about the reasons for the unsuccessful implementation, and knowledge on how to facilitate CPR training in schools is warranted. ${ }^{15} 1618$ Few studies have tried to identify barriers to implementation of CPR training in schools. These studies primarily identified organisational factors such as lack of time, funds, curriculum pressure, training materials and teacher training, but did not provide a deeper understanding of these factors or how to change them. ${ }^{16}{ }^{19-21}$ Following 8 years of legislation mandating CPR training, we aimed to explore barriers to implementation of CPR training in Danish secondary schools. We used qualitative methods as they offer the possibility of providing an in-depth and nuanced understanding of the barriers.

\section{METHODS}

\section{Study design}

This is a qualitative study based on interviews with school leadership and teachers, since both are important actors in the implementation of changes in schools. We used qualitative methods as they can reveal new information, uncover dimensions such as beliefs, thoughts and motivations and provide insight into complex relations, ${ }^{22-24}$ which can be critical in order to understand what hinders the implementation of CPR training in schools. The interviews were conducted during November 2012 to January 2013 at secondary schools in Denmark (6th grade to 9th grade students, age 12-16).

\section{Sampling and participants}

To reach maximum variation of the study sample, we used a strategic sampling strategy to select schools, ${ }^{24}$ including (1) schools with and without recent experience in CPR training of students, (2) public and private schools and (3) schools near to and far from hospitals. We asked principals to participate in the study through a telephone call, but they could delegate participation to a middle manager (eg, administrative managers and section managers), if it was relevant according to their area of responsibility. Principals and middle managers are all referred to as school leadership. Teachers were recruited only at schools with participating school leadership. School leadership was asked to give access to between four and eight secondary schoolteachers. We stopped recruiting schools when data saturation was achieved, which is defined as the point at which no new or relevant data emerge. ${ }^{23}$ The study was conducted at eight schools, and the study population comprised 25 participants, 9 school leadership members and 16 teachers. They varied in age, prior CPR training and other background variables (table 1). Two school leaders and seven teachers had never taken a CPR course.

Only 3 of 16 teachers had conducted CPR training of students, with all three using a CPR training kit including a video-based self-instruction. One of these teachers, who was a certified instructor, had also provided a full week's basic life support training to students without using such a kit. Another three teachers and one school leader had observed CPR training of students.

\section{Data collection}

The two primary investigators ( $\mathrm{LZ}$ and $\mathrm{CMH}$ ) carried out individual interviews with school leadership and one interview with two school leaders from the same school,

\begin{tabular}{|c|c|c|}
\hline & $\begin{array}{l}\text { School leadership } \\
n=9\end{array}$ & $\begin{array}{l}\text { Teachers } \\
n=16\end{array}$ \\
\hline \multicolumn{3}{|l|}{ Sex } \\
\hline Women & 2 & 12 \\
\hline Men & 7 & 4 \\
\hline \multicolumn{3}{|l|}{ Age } \\
\hline$<55$ & 5 & 8 \\
\hline$\geq 55$ & 4 & 8 \\
\hline Mean & 53 years & 46 years \\
\hline \multicolumn{3}{|l|}{ Years teaching } \\
\hline$<15$ & 3 & 9 \\
\hline$\geq 15$ & 6 & 7 \\
\hline \multicolumn{3}{|l|}{ CPR course } \\
\hline Yes, incl. AED use & 1 & 3 \\
\hline Yes, excl. AED use & 6 & 6 \\
\hline No & 2 & 7 \\
\hline \multicolumn{3}{|l|}{ Position } \\
\hline Principal & 5 & - \\
\hline $\begin{array}{l}\text { Administrative } \\
\text { manager }\end{array}$ & 2 & - \\
\hline Section manager & 2 & - \\
\hline
\end{tabular}


along with four focus group interviews with three to five teachers in each group and one individual interview with a teacher. The interviews were conducted at the schools, and field notes were made following the interviews. School leadership and teachers were interviewed separately due to the power imbalance between them. Individual interviews with school leadership were chosen due to logistical considerations. Further, they are well suited for sensitive topics, ${ }^{23}{ }^{24}$ such as admitting not having implemented mandatory CPR training. Focus group interviews with teachers were preferred, because they elucidate different positions and uncover the degree of consensus or diversity on a topic. Participants can present their own views and comment on others, responses can be compared, and positions can evolve in the interaction during the interview. ${ }^{23}{ }^{24}$ The semistructured interview protocol (in online supplementary data) was developed by discussion in the research team including professionals from anthropology (TTT, MHR), medicine $(\mathrm{CMH}, \mathrm{FF}$ and $\mathrm{CTP})$ and public health (LZ) and was inspired by the theory of planned behaviour, using concepts such as perceived behavioural control, ${ }^{25}$ and by existing literature exploring barriers to implementation of CPR training in school. ${ }^{19}{ }^{20}$ We also included questions on beliefs about CPR outside the school context and were open and flexible to issues that the interviewees brought up themselves. The interview protocol used for school leadership and teachers only differed marginally. The individual interviews lasted $45 \mathrm{~min}$ to $1 \frac{1 / 2}{\mathrm{~h}}$, and each focus group session lasted $1 \frac{1}{2}-2 \mathrm{~h}$. All interviews were audio recorded and transcribed (LZ).

\section{Data analysis}

The analysis, taking an inductive descriptive approach, was data-driven and guided by conventional thematic analysis strategies identifying regular patterns of meaning both within and across the interviews, thus allowing us to specify major themes in the material. ${ }^{23} 24$ The transcripts were read repeatedly by the two primary investigators (LZ and CMH) to get an overall impression and to become familiar with the diversity of the data. They separately used open coding for each paragraph of the transcriptions to discover categories, characteristics and dimensions in the material, ${ }^{24}$ and met to discuss and refine the categories. The coding was then discussed with the research team (LZ, CMH, TTT and MHR), and related categories were reduced to form major themes with subcategories. Each interview was coded (LZ) applying a colour for each theme. Each colour/theme was transferred to another document and colour divided into subthemes. Within these (sub) themes, similarities and differences in the statements both within and across interviews were identified. Selections of quotes were based on how well they illustrated and elucidated the themes and important points identified in the complete material.

\section{Ethics}

Verbal consent was obtained from all individuals participating in the study. All participants were informed about the aim of the study and were assured that participation was voluntary and results would be anonymous, that we had no intention of evaluating any specific school, school leader or teacher, and that refusal to participate would be without any consequences. Only persons attached to the research team had access to the data, and full names of the participants were kept separated from the transcripts. ${ }^{26}$

\section{RESULTS}

Four schools were currently teaching students CPR. However, only one of these schools was providing CPR training systematically and ensuring that all students were trained in CPR before graduating from secondary school. At the three other schools, CPR training seemed to be unorganised, irregular and coincidental. Not all interviewees knew that CPR training of students was mandatory. At the schools without CPR training, the school leader knew about the legislation. Further, only one of the schools without CPR training was a private school, to which the legislation does not fully apply (table 2). This demonstrates that barriers, besides lack of knowledge about CPR legislation, are important to implementation of CPR training. Although school leadership and teachers had a positive attitude towards the idea of CPR training in schools, their numerous obligations and general lack of time raised questions as to whether they would prioritise it as they prioritised core subjects such as Maths and English. Nevertheless, other subjects of the same status as CPR training, such as sex education and bicycle Safety Education, were already systematically implemented. We identified three main themes covering barriers to CPR training: (1) insecurity

Table 2 CPR training at the participating schools, the study populations' knowledge of the legislation on CPR training in school and school type (private/public)

\begin{tabular}{lllll}
\hline \multicolumn{5}{c}{ Knowledge of } \\
School & $\begin{array}{l}\text { Current CPR } \\
\text { training }\end{array}$ & $\begin{array}{l}\text { Schislation } \\
\text { School }\end{array}$ & School \\
leadership & Teachers & type \\
\hline 1 & Yes & Yes & Yes & Public \\
2 & Yes & No & - & Public \\
3 & Yes & No & Some & Public \\
4 & Yes & No & - & Private \\
5 & No & Yes & Yes & Private \\
6 & No & Yes & Some & Public \\
7 & No & Yes & Some & Public \\
8 & School & Yes & - & Public \\
\multicolumn{5}{l}{} \\
\hline \multicolumn{7}{l}{ lndicates that teachers were not interviewed at these schools. } \\
AED, automatic external defibrillator; CPR, cardiopulmonary \\
resuscitation.
\end{tabular}


about one's own CPR instruction skills, (2) insecurity about one's own CPR skills and (3) organisation of CPR training, which are all interrelated.

\section{Insecurity about one's own CPR instruction skills}

School leadership and teachers considered it important for implementation and sustainability of CPR training that teachers conduct CPR training of students. However, they thought teachers were currently incapable of training students. Illustrative of this finding, a school leader and teacher stated:

I could also say that we must teach all our students to swim, and that would also depend on the number of teachers who already know how to swim, and how many have passed the swim test. (School leader, school 3)

I would not be able to do it. I would not be able to teach that $[\mathrm{CPR}]$. I would have no idea about how to do it. (Teacher 1, school 6)

A CPR course including practical training was considered essential to train students in CPR. A teacher expressed this by saying:

I know it's a bad comparison, but in your medical terms it may serve as a good illustration. You can also read about surgery, but it would be nice to have tried to use a scalpel. This is how I would feel. I'd feel much the same way. (Teacher 2, school 6)

However, a CPR course was not necessarily regarded as sufficient to enable teachers to conduct CPR training of students. CPR training was perceived to be unlike other teaching subjects because it is a matter of life and death, and teaching students correct and adequate CPR skills was thus perceived to be of critical importance. Teachers' CPR skills were therefore regarded as extraordinarily important. School leadership and teachers considered an up-to-date CPR course of a certain length (eg, more than $4 \mathrm{~h}$ ) a prerequisite to train students. Still, not all would feel capable because of fear of teaching the students something wrong. As one of the teachers described it:

Imagine if I taught the students something wrong. I could not bear that. Imagine if I had shown a student something wrong, and they performed CPR that actually made it worse. I would never be able to forgive myself. (Teacher 3, who attended a CPR course $1 \frac{1}{2}$ years ago, school 7)

Some even argued that teachers should be certified instructors to train students. The few interviewees who did not think extensive skill requirements were needed to train students were confident about training students in CPR. High expectations were followed by expectations of high costs needed to qualify teachers to train students, because it shaped their thoughts about the length, type and frequency of courses needed or costs needed to hire external experts.
Insecurity about one's own CPR skills

School leadership and teachers' general considerations about CPR played an important role in relation to their insecurity about their own ability to train students in CPR. They felt a moral obligation to act in case they witnessed a cardiac arrest, but lacked confidence in their own CPR skills which were related to three aspects concerning skill requirements: CPR skills need to be acquired, CPR guidelines frequently change, and CPR skills rapidly decline. (1) The interviewees considered it necessary to acquire CPR skills through a CPR course. This is illustrated by a school leader who said:

Personally, I should have enrolled myself in the [CPR] course. I probably should have. I cannot perform CPR, and I wish I could. (School leader, school 7)

(2) The interviewees described how the CPR algorithm and specific parts of the algorithm had changed during their lifetime (eg, removal of hitting the chest and changes in the compression-to-ventilation ratio). It was considered essential for survival to perform CPR in accordance with the latest guidelines. As two teachers said:

There you go, 30:2, yes okay. There has been a breakthrough in terms of knowledge, and such things may be crucial. So I do not feel competent, because I do not have the latest knowledge. (Teacher 2, school 6)

Skills in relation to this [CPR]. It is important in terms of whether people survive. So it is rather important to do it correctly. (Teacher 3, school 3)

(3) CPR skills were considered to decline rapidly, and skills acquired from former CPR courses were considered invalid. As one of the teachers explained it:

I have actually completed a big first aid course three times with exams and everything, and I have done it again, because I simply cannot remember it. Now, I cannot remember it again, because it has been ten years since my last course. (Teacher 2, school 7)

One school leader even expressed that laypersons could not be expected to perform CPR, but only health professionals should do it. Laypersons' most important role was calling for professional help:

Who do I get? How do I quickly get professional help? This must be the most important task, and then you could say that it would also be good if there was someone who could perform CPR. But I do not think it is something you can expect. (School leader, school 4)

School leadership and teachers' perception of extensive requirements to perform CPR and insecurity with one's own CPR skills were transferred to their thoughts about training students, and can thus be identified as a barrier to implementation of CPR training of students. 
Few other interviewees took another position as illustrated by a teacher saying:

You cannot make mistakes. The man is dead. You cannot kill him. (Teacher 4, school 1)

These interviewees were more confident in their own CPR skills and were more self-confident about training students, and it seemed to be regardless of previous CPR training.

\section{Organisation of CPR training \\ Type of instructor}

School leadership and teachers were reluctant to train students in CPR unless they acquired the skills they thought were needed to be able to conduct the training. Otherwise, an external instructor was considered strictly necessary. Owing to the extensive proficiency level school leaders and teachers expected, some thought teachers would not be able to train students as well as external instructors, irrespective of prior CPR training:

It results in a greater impact for students if an external instructor conducts the training. Even if the teachers get a [CPR] course, there will always be questions they cannot answer. And when people and teachers feel there are things they cannot answer, then it [the training] may not be that convincing. (School leader, school 4)

On the other hand, interviewees believed teachers were more qualified when it came to pedagogical skills needed to carry out the training. Also, they emphasised that it would reduce scheduling difficulties with external instructors and expenses to hire them and result in more sustainable CPR training. However, expenses for CPR training of teachers were also viewed as important. As an alternative to limit expenses, interviewees suggested that CPR training could be organised by having CPR coordinators (teachers) at the school, arguing that not all teachers needed these skills to educate all students in CPR. This is illustrated by a teacher saying:

We do not all need to have the same skills. That's why we have each other. We can draw on each other's skills. So we do not need that. We cannot all be woodwork teachers either, or German teachers. When we are going to teach something with German, we ask the German teacher. (Teacher 4, school 1)

Nevertheless, some teachers were also opposed to this, because it was assumed that having a CPR coordinator meant that not all teachers would receive the CPR training courses they requested in order to be able to deal with emergency situations occurring at the school (for their own skills and not training students).

\section{Training material}

Training material was considered essential to train students in CPR. Training kits including a video-based self-instruction seemed to lower school leaders' and teachers' expectations of skill requirements to conduct CPR training, among those who were familiar with them. This is illustrated by a teacher explaining how the DVD took over the role as the main teacher, thus requiring fewer skills by the instructor:

You are not responsible for teaching and introducing it all. The DVD does that (...). We do not need to perform so much, we become more like assisting teachers, you may say. (Teacher 2, school 1)

Some of those familiar with CPR training kits even stated that everyone could teach CPR, regardless of CPR skills, if provided with such training material. Nevertheless, others also familiar with CPR training kits emphasised that they themselves and others would feel more comfortable if they were provided with a CPR course and acknowledged that, even so, some would not feel capable of training students in CPR. School leadership and teachers not familiar with CPR training kits explained that they would not try to use such material unless they felt confident that they possessed the required CPR skills. There was some resistance towards video-based training as some considered it too artificial and less effective. This attitude was also present among interviewees familiar with the material. Further, many did not know that CPR training kits were available to Danish schools free of charge.

\section{DISCUSSION}

\section{Main findings}

This is the first study to provide in-depth information about barriers needed to be addressed to ensure CPR training in schools. Our main findings were that school leadership and teachers considered it important for implementation and sustainability of CPR training that teachers conduct CPR training of students. However, they preferred external instructors to train students, unless teachers acquired the CPR skills which they considered were needed. They considered CPR training to differ substantially from other teaching subjects because it is a matter of life and death, and they therefore believed extraordinary skills were required for conducting CPR training of students. This was mainly rooted in their insecurity about their own CPR skills. CPR training kits seemed to lower expectations of skill requirements to conduct CPR training, but only among the few who were familiar with such kits.

\section{Strengths and weaknesses of this study}

The qualitative design of our study allowed us to gain an in-depth and nuanced understanding of why implementation of CPR training has been unsuccessful despite mandating legislation. We were able to reveal new important barriers (eg, that school leadership and teachers believe extraordinary skills are required for conducting CPR training of students), get insight into the 
complex relationship between barriers (eg, that school leadership and teachers' expectations of extensive skill requirements to perform CPR and the accompanying insecurity with their own CPR skills are transferred to their thoughts about training students), and to reach an understanding of the underlying mechanisms related to previously identified barriers (eg, the underlying mechanisms to the barrier lack of teacher training). We managed to obtain a broad representation of schools and interviewees, to portray different positions, and reached data saturation. Nevertheless, the views of the participating school leadership and teachers could differ from those who did not participate. The study did not explore how schools currently providing CPR training of students had implemented and conducted the training, though this could inspire and give directions for other schools. As such, this is a question for further research.

\section{Comparison with the existing literature}

The current literature emphasises lack of time, funds, curriculum pressure, training materials and teacher training as barriers for implementation of CPR training in schools. ${ }^{16} 17^{19-21}$ Our study is in accordance with these findings, but importantly, our findings provide novel information to understand and target these previously identified barriers and also identified previously unknown barriers.

In many countries, schoolteachers are expected to conduct CPR training, including in Denmark. ${ }^{17} 2728$ Also, healthcare professionals argue that skills can be learnt quickly and recommend that teachers should provide CPR training, because they can generate more sustainable training. ${ }^{15} 192829$ Importantly, we found that generally teachers and school leadership agree that teachers should conduct this training, but only if they acquire the CPR skills they consider are needed. Otherwise, external instructors were considered strictly necessary. Our findings that school leadership and teachers are very insecure about their own proficiency level and whether they are competent enough to train students do not seem to be restricted to Denmark. Previous studies reported that teachers did not feel they had the required training to deliver CPR training, ${ }^{17}{ }^{21}$ and most school leaders thought CPR training should be provided by external instructors, ${ }^{30}$ but the studies did not describe the underlying mechanisms for this. Our findings that school leadership and teachers expect extensive CPR instruction skills are required to train students might explain why teachers have been found to be unwilling to train students, ${ }^{27} 31$ despite a high interest in CPR training, ${ }^{30}{ }^{31}$ and despite previous CPR training. ${ }^{27}$ The mismatch in expectations of skill requirements between healthcare professionals and school staff is a key finding to understanding the barriers to implementing CPR training in schools. There are currently no clear guidelines for schools regarding what proficiency level is required to train students in CPR, or who should conduct the training.
Previous studies have identified training material as important for implementation of CPR training. ${ }^{19}{ }^{21}$ Our study indicates that training kits including a videobased self-instruction have the potential to increase teachers' confidence in training students in CPR, as such kits seemed to lower their expectations of skill requirements. However, this was only expressed among those familiar with training kits. It is problematic that many interviewees did not know such training kits were available to Danish schools free of charge. Several organisations offer different types of training material to schools and CPR courses for students and teachers in a varying price range. There is no overview of this to schools.

Our findings on the link between perceived CPR instruction skills and perceived ability to perform CPR are not restricted to Denmark. A Belgian study found that the majority of teachers willing to teach CPR felt capable to act in a cardiac arrest situation. ${ }^{27}$ However, only $34 \%$ of teachers felt capable of providing CPR, and only $47 \%$ among those with previous CPR training. ${ }^{27}$ Our study provides new insight into this, as we show that school leaders' and teachers' insecurity with their own ability to perform CPR is shaped by expectations of comprehensive skill requirements and because they consider CPR skills acquired from former CPR courses to be outdated. Medical experts recommend that a skills assessment and, if required, a skills refresher course should be undertaken more often than every 12-24 months. ${ }^{32}$ Our study suggests that a strict focus on correct CPR skills may cause laypersons to doubt their own CPR skills, which is supported by previous studies showing that fear of performing CPR incorrectly decreases the willingness of bystanders to start $\mathrm{CPR}^{32} 33$ and may hinder CPR training in schools. Importantly, regular retraining might not be necessary for bystander CPR to be effective. ${ }^{34}$ To simplify skill requirements for lay bystanders, the American Heart Association and the European Resuscitation Council introduced compression-only (or hands-only) CPR in 2010 for untrained or not proficient bystanders under some circumstances. ${ }^{35-38}$ The Danish Resuscitation Council has, however, not included compression-only in their guidelines. ${ }^{39}$ Nevertheless, we found that awareness of frequently changing guidelines contributed to the interviewee's insecurity; thus, compression-only CPR may not necessarily enable school leaders and teachers to feel more competent.

\section{Implications for practice and policy}

It is a public health goal that all students receive CPR training to raise bystander $\mathrm{CPR}$ rates and thereby increase survival after OHCA. This study clearly demonstrates a need for specification of what is required to be qualified to train students in CPR, to communicate this to the schools, and to provide teachers with these skills in order to achieve this goal. It is paramount to address school leaders' and teachers' expectations of extensive 
skill requirements for conducting CPR training of students and their insecurity with their own CPR instruction skills. In line with this, there is a great need to simplify messages about skill requirements to perform CPR and emphasise the importance of providing CPR, regardless of the correct CPR technique. Lastly, it is important to familiarise teachers with training kits.

\section{CONCLUSIONS}

School leadership and teachers considered it important for sustainability of CPR training that teachers conduct CPR training of students. However, they preferred external instructors, unless teachers acquired the CPR skills which they considered were needed. They expected that extraordinary skills are required to conduct CPR training, because they regarded this to differ substantially from other teaching subjects since it is a matter of life and death. This was mainly rooted in their insecurity about their own CPR skills. To facilitate implementation of CPR training in schools, it is necessary to have clear guidelines regarding the required proficiency level to train students in CPR, to provide teachers with these skills, and to underscore that extensive skills are not required to provide CPR. Further, it is important to familiarise teachers with CPR training kits.

\section{Author affiliations}

${ }^{1}$ Centre for Intervention Research, National Institute of Public Health, University of Southern Denmark, Copenhagen, Denmark

${ }^{2}$ Department of Cardiology, Copenhagen University Hospital Gentofte, Gentofte, Denmark

${ }^{3}$ Emergency Medical Services, Capital Region of Denmark, University of Copenhagen, Copenhagen, Denmark

${ }^{4}$ Department of Health Science and Technology, Aalborg University, Aalborg East, Denmark

Acknowledgements The authors are grateful to the school leadership and teachers participating in the study.

Contributors LZ drafted the manuscript, recruited participants and transcribed the interviews. LZ and CMH collected the data. LZ, CMH, TTT, FF and CTP were involved in the study conception and design. LZ, CMH, TTT and MHR analysed the data. All authors took part in interpretation of the data, have critically revised the manuscript and approved the final manuscript.

Funding This work was supported by the Danish Foundation TrygFonden (grant number 103291); and the Health Insurance Foundation, Denmark (grant number 2012B189). They had no influence on the study or manuscript.

\section{Competing interests None declared.}

Ethics approval The study was approved by the Danish Data Protection Agency J.nr. 2012-54-0217. In Denmark, this type of study does not require formal ethical approval. ${ }^{26}$

Provenance and peer review Not commissioned; externally peer reviewed.

Data sharing statement No additional data are available.

Open Access This is an Open Access article distributed in accordance with the Creative Commons Attribution Non Commercial (CC BY-NC 4.0) license, which permits others to distribute, remix, adapt, build upon this work noncommercially, and license their derivative works on different terms, provided the original work is properly cited and the use is non-commercial. See: http:// creativecommons.org/licenses/by-nc/4.0/

\section{REFERENCES}

1. Georgiou M, Lockey AS. ERC initiatives to reduce the burden of cardiac arrest: the European cardiac arrest awareness day. Best Pract Res Clin Anaesthesiol 2013;27:307-15.

2. Mozaffarian D, Benjamin EJ, Go AS, et al. Heart disease and stroke statistics-2015 update: a report from the American Heart Association. Circulation 2015;131:e29-322.

3. Berdowski J, Berg RA, Tijssen JG, et al. Global incidences of out-of-hospital cardiac arrest and survival rates: systematic review of 67 prospective studies. Resuscitation 2010;81:1479-87.

4. Herlitz J, Svensson L, Holmberg S, et al. Efficacy of bystander CPR: intervention by lay people and by health care professionals. Resuscitation 2005;66:291-5.

5. Wissenberg M, Lippert FK, Folke F, et al. Association of national initiatives to improve cardiac arrest management with rates of bystander intervention and patient survival after out-of-hospital cardiac arrest. JAMA 2013;310:1377-84

6. Chan PS, McNally B, Tang F, et al. Recent trends in survival from out-of-hospital cardiac arrest in the United States. Circulation 2014;130:1876-82.

7. Sasson C, Rogers MA, Dahl J, et al. Predictors of survival from out-of-hospital cardiac arrest: a systematic review and meta-analysis. Circ Cardiovasc Qual Outcomes 2010;3:63-81.

8. Bohn A, Lukas RP, Breckwoldt J, et al. 'Kids save lives': why schoolchildren should train in cardiopulmonary resuscitation. Curr Opin Crit Care 2015;21:220-5.

9. Bottiger BW, Van Aken H. Training children in cardiopulmonary resuscitation worldwide. Lancet 2015;385:2353.

10. Cave DM, Aufderheide TP, Beeson J, et al. Importance and implementation of training in cardiopulmonary resuscitation and automated external defibrillation in schools: a science advisory from the American Heart Association. Circulation 2011;123: 691-706.

11. IOM Strategies to Improve Cardiac Arrest Survival, $A$ time to act. Washington DC: Institute of Medicine 2015.

12. Lockey AS, Georgiou M. Children can save lives. Resuscitation 2013;84:399-400.

13. Undervisningsministeriet Fælles Mål 2009 Færdselslære. Faghæfte 20. Undervisningsministeriets håndbogsserie. 2009.

14. Undervisningsministeriet Bekendtgørelse om formål, trin- og slutmål for folkeskolens fag og emner BEK nr 748 af 13/07/2009. 2009. https://www.retsinformation.dk/forms/R0710.aspx?id=125973 (accessed 4 Jan 2016).

15. Plant N, Taylor K. How best to teach CPR to schoolchildren: a systematic review. Resuscitation 2013;84:415-21.

16. Hart D, Flores-Medrano O, Brooks S, et al. Cardiopulmonary resuscitation and automatic external defibrillator training in schools: "is anyone learning how to save a life?." CJEM 2013;15:270-8.

17. Væggemose U, Folke F, Ehlers L, et al. Hiertestart $i$ Danmarkstatus og udviklingsmuligheder $i$ et MTV-perspektiv. Århus: MTV og Sundhedstjenesteforskning, 2008.

18. Engeland A, Røysamb E, Smedslund G, et al. Effects of first-aid training in junior high schools. Inj Control Saf Promot 2002;9:99-106.

19. Lafferty C, Larsen PD, Galletly D. Resuscitation teaching in New Zealand schools. N Z Med J 2003;116:U582.

20. Reder S, Quan L. Cardiopulmonary resuscitation training in Washington state public high schools. Resuscitation 2003;56:283-8.

21. Lockey AS, Barton K, Yoxall H. Opportunities and barriers to cardiopulmonary resuscitation training in English secondary schools. Eur J Emerg Med 2015. [Epub ahead of print]. doi:10.1097/MEJ. 0000000000000307

22. Malterud K. The art and science of clinical knowledge: evidence beyond measures and numbers. Lancet 2001;358:397-400.

23. Mason J. Qualitative researching. London: Sage Publication, 2007.

24. Patton M. Qualitative research \& evaluation methods. London: Sage Publication, 2002.

25. Ajzen I. The theory of planned behavior. Organ Behav Hum Dec 1991;50:179-211.

26. The Danish Data Protection Agency. Danish Act on Processing of Personal Data. 2015. http://www.datatilsynet.dk/lovgivning/ persondataloven (accessed 4 Jan 2016).

27. Mpotos N, Vekeman E, Monsieurs K, et al. Knowledge and willingness to teach cardiopulmonary resuscitation: a survey amongst 4273 teachers. Resuscitation 2013;84:496-500.

28. Ammirati C, Gagnayre R, Amsallem C, et al. Are schoolteachers able to teach first aid to children younger than 6 years? A comparative study. BMJ Open 2014;4:e005848.

29. Lester CA, Weston CF, Donnelly PD, et al. The need for wider dissemination of CPR skills: are schools the answer? Resuscitation 1994:28:233-7. 
30. Miró O, Jiménez-Fábrega $\mathrm{X}$, Espigol G, et al. Teaching basic life support to 12-16 year olds in Barcelona schools: views of head teachers. Resuscitation 2006;70:107-16.

31. McCluskey D, Moore P, Campbell S, et al. Teaching CPR in secondary education: the opinions of head teachers in one region of the UK. Resuscitation 2010;81:1601.

32. Mancini ME, Soar J, Bhanji F, et al. Part 12: education, implementation, and teams: 2010 international consensus on cardiopulmonary resuscitation and emergency cardiovascular care science with treatment recommendations. Circulation 2010;122 (Suppl 2):S539-581.

33. Sasson C, Haukoos JS, Bond C, et al. Barriers and facilitators to learning and performing cardiopulmonary resuscitation in neighborhoods with low bystander cardiopulmonary resuscitation prevalence and high rates of cardiac arrest in Columbus, $\mathrm{OH}$. Circ Cardiovasc Qual Outcomes 2013;6:550-8.

34. Vaillancourt C, Stiell IG, Wells GA. Understanding and improving low bystander CPR rates: a systematic review of the literature. CJEM 2008; 10:51-65
35. Berg RA, Hemphill R, Abella BS, et al. Part 5: adult basic life support: 2010 American Heart Association Guidelines for Cardiopulmonary Resuscitation and Emergency Cardiovascular Care. Circulation 2010;122(Suppl 3):S685-705.

36. Koster RW, Baubin MA, Bossaert LL, et al. European Resuscitation Council Guidelines for Resuscitation 2010 section 2. Adult basic life support and use of automated external defibrillators. Resuscitation 2010;81:1277-92.

37. Perkins GD, Handley AJ, Koster RW, et al. European Resuscitation Council Guidelines for Resuscitation 2015: section 2. Adult basic life support and automated external defibrillation. Resuscitation 2015;95:81-99.

38. Travers AH, Perkins GD, Berg RA, et al. Part 3: adult basic life support and automated external defibrillation: 2015 international consensus on cardiopulmonary resuscitation and emergency cardiovascular care science with treatment recommendations. Circulation 2015;132(Suppl 1):S51-83.

39. Danish Resuscitation Council. http://genoplivning.dk/ (accessed 7 Jan 2016) 